\title{
Caracterização geotécnica e geoambiental da bacia do Córrego São Pedro-Uberlândia/MG: contribuição para elaboração do plano de drenagem urbana
}

\author{
Geotechnical and geoenvironmental characterization of São Pedro \\ stream basin - Uberlândia/MG: a contribution to prepare the urban \\ drainage plan
}

\author{
Ana Clara Mendes Caixeta ${ }^{1}$ \\ Vanderlei de Oliveira Ferreira ${ }^{2}$ \\ Luiz Nishiyama ${ }^{3}$
}

\begin{abstract}
Resumo
O presente artigo expõe resultados de uma pesquisa dedicada à realização de uma caracterização geotécnica e geoambiental da bacia do córrego São Pedro, situada na área urbana de Uberlândia/MG, a partir dos atributos e propriedades do meio físico, com vista à utilização do solo como um meio de infiltração das águas pluviais. A metodologia utilizada concentra-se no mapeamento analítico, gerando documentos cartográficos elaborados e analisados individualmente. Além disso, é feita a caracterização de materiais inconsolidados (in situ e laboratório) e ensaios do coeficiente de permeabilidade (k) (in situ com o permeâmetro Guelph). De posse de todos os dados foi feita a análise quali-quantitativa das características do meio físico pelo estudo de seus atributos e sua representação em mapas, privilegiando variáveis relacionadas à avaliação de processos de infiltração e escoamento. Para a área da bacia do córrego São Pedro foram obtidos valores de $\mathrm{k}$ variando entre as ordens de grandeza de $10^{-4}$ a $10^{-5} \mathrm{~cm} / \mathrm{s}$. O mapa de adequabilidade à infiltração apresentou ser não adequado ou pouco adequado nas áreas mais próximas aos canais e na foz do córrego principal. Os terrenos situados próximos aos divisores de água da bacia apresentam-se muito adequados. O centro da bacia e a região localizada entre os córregos Jataí e Lagoinha são também muito adequadas à infiltração. Estas áreas com maior adequabilidade são apropriadas à implantação de medidas estruturais e não estruturais, visando reduzir riscos a inundações. Assim, de posse destes mapas geoambientais esperase contribuir para o planejamento urbano na área de estudo.

Palavras-chave: mapeamento geoambiental. Coeficientes de
\end{abstract} permeabilidade. Infiltração. Inundações.

\footnotetext{
${ }^{1}$ Laboratório de Geoprocessamento e Sensoriamento Remoto (LGSR), Centro de Estudos em Geociências (CeGeo), Instituto de Ciência e Tecnologia (ICT), Universidade Federal dos Vales do Jequitinhonha e Mucuri (UFVJM), Diamantina, Minas Gerais, Brasil. anaclara_caixeta@hotmail.com ${ }^{2}$ Laboratório de Cartografia e Sensoriamento Remoto (LACAR), Universidade Federal de Uberlândia (UFU), Uberlândia, Minas Gerais, Brasil. vanderlei.ferreira@ufu.com

${ }^{3}$ Museu de Minerais e Rochas, Universidade Federal de Uberlândia (UFU), Uberlândia, Minas Gerais, Brasil. luiz.nishiyama@gmail.com

Artigo recebido em: 13/12/2018. Aceito para publicação em: 03/06/2019.
} 


\begin{abstract}
This article presents the results of a research aimed at geotechnically and geoenvironmentally characterizing the São Pedro stream basin, located in Uberlândia/MG, from the physical environment's attributes and properties, with a view to using land as a means of rainfall infiltration. The used methodology focuses on analytical mapping and generating cartographic documents that are individually elaborated and analyzed. Besides that, the characterization of unconsolidated materials (in situ and in laboratory) and coefficient of permeability (k) tests (in situ with a Guelph permeameter) were performed. With this data at hands, a qualiquantitative analysis of the physical environment's features was made through the study of its attributes and their representation in maps. Variables related to infiltration and runoff processes were privileged. For the area of the São Pedro stream basin, values of $\mathrm{k}$ varying between $10^{-4}$ and $10^{-5} \mathrm{~cm} / \mathrm{s}$ were found. The adequacy-to-infiltration map showed the areas next to the streams and in the stream's mouth as non-adequate or slightly-adequate. On the other hand, the areas close to the drainage divides of the basin showed to be highly-adequate. The center of the basin and the region between the Jataí and the Lagoinha streams are also highly-adequate to infiltration. These areas with higher adequacy are appropriate to the implementation of structural and non-structural measures that seek to reduce flood risks. Thus, we hope to contribute to urban planning in this study area through these geoenvironmental maps.
\end{abstract}

Keywords: geoenvironmental mapping. coefficients of permeability. Infiltration. Floods.

\title{
Introdução
}

O Plano de Drenagem Urbana (PDU) deve ser um componente do Plano Diretor de Planejamento Urbano de uma cidade (TUCCI, 1997, p.9). Nele deve estar presente um mapeamento geotécnico e geoambiental resultante de minucioso processo de investigação e avaliação qualiquantitativa das características do meio físico por meio do estudo de seus atributos e sua representação em mapas.

O processo de planejamento exige várias ferramentas. Dentre elas, utiliza-se o mapeamento geotécnico e geoambiental. Este pode ser compreendido como um processo de investigação e avaliação qualiquantitativa das características do meio físico pelo estudo de seus atributos e sua representação em mapas. 
Mapas geoambientais integrados ao mapeamento geotécnico ampliam os componentes e as finalidades de análise ambiental, definindo tanto as potencialidades quanto as limitações do planejamento territorial. Após esta gama de mapas geoambientais gerados, é possível contribuir com dados e informações do meio físico e ambiental para o planejamento territorial. Portanto, espera-se contribuir para que os gestores determinem um uso adequado do solo.

A área de estudo deste trabalho é a bacia do córrego São Pedro, localizada na cidade de Uberlândia-MG, que sofre com inundações recorrentes. As principais causas decorrem da ocupação urbana intensa, que culminou com a impermeabilização excessiva do solo. Além disso, o córrego sofreu uma modificação na sua configuração natural com a canalização fechada, ocorrida na década de 1980, e sobre ele foi edificada a Avenida Rondon Pacheco.

A pesquisa relatada no presente artigo objetivou realizar uma caracterização geoambiental, com ênfase nos aspectos geotécnicos da bacia do córrego São Pedro, em Uberlândia/MG, com vista à utilização do solo como um meio de infiltração das águas. Foram priorizadas as áreas com baixa densidade de ocupação ou em vias de ocupação, visando contribuir para o plano diretor de drenagem urbana.

\section{Área de estudo}

A bacia, localizada quase totalmente na área urbana de Uberlândia/MG, apresentando área de 48,201 $\mathrm{km}^{2}$. A drenagem fluvial, conforme apresentado na Figura 1, ocorre por meio dos córregos São Pedro, Jataí, Lagoinha e Mogi. 
Figura 1 - Localização da bacia do córrego São Pedro, em Uberlândia/MG
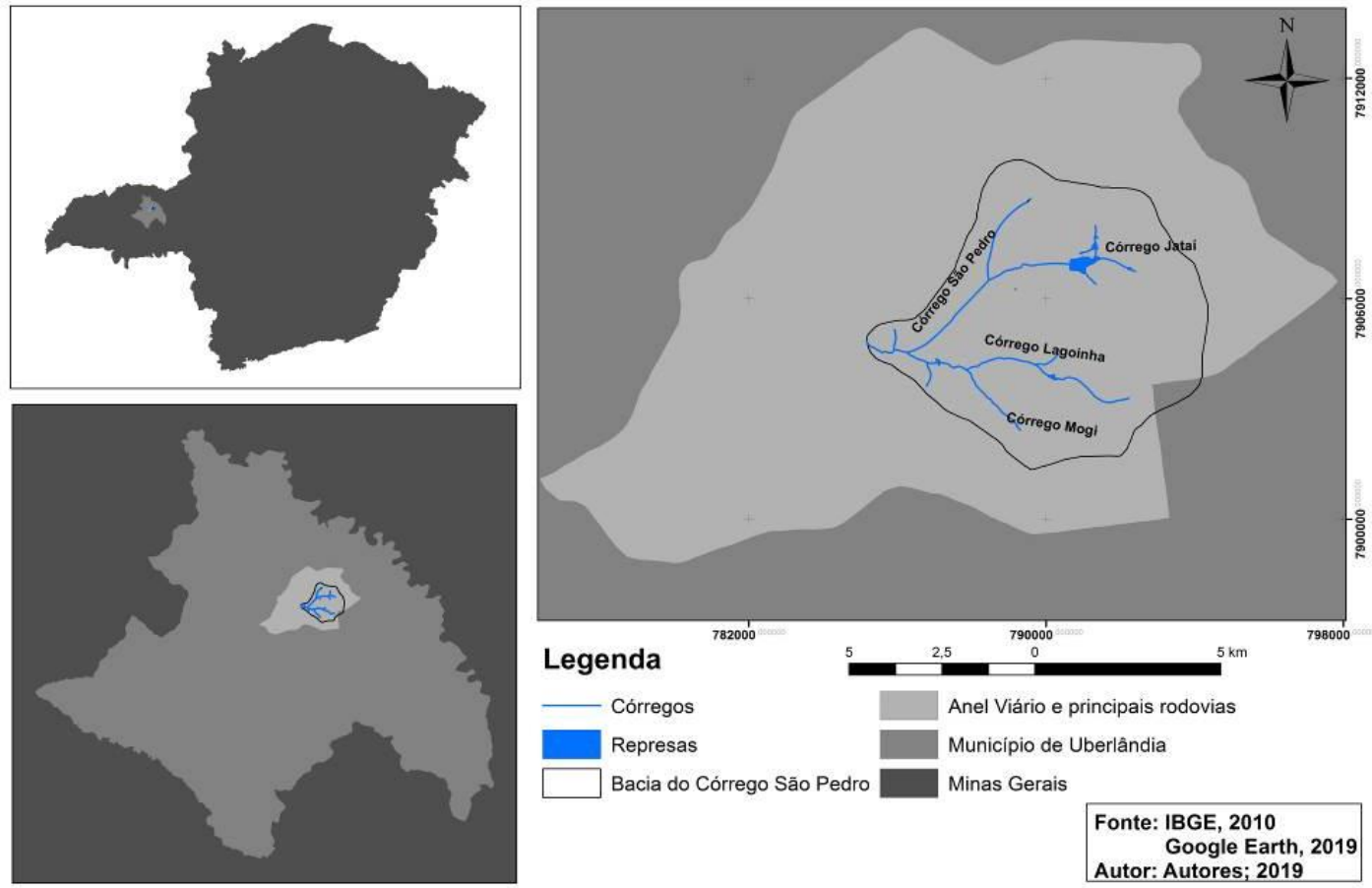

Elaborado: Autores, 2019

\section{Metodologia}

A base cartográfica primária foi construída por meio das cartas topográficas do Ministério do Exército de 1984 na escala 1:25000: Cachoeira do Sucupira: SE-22-Z-B-VI-4-SO; Córrego das moças: SE-22-Z-B-VI-3-NE; Pau Furado: SE-22-Z-B-VI-4-NO e Uberlândia: SE-Z-B-VI-3-SE. Por meio do software Arcgis 10®10.2.2, elaborou-se o mosaico para obtenção de um único arquivo com os limites da área de estudo. Assim, foi possível realizar a vetorização das curvas de nível e os pontos cotados. Já a vetorização da drenagem, visto que a bacia está inserida na área urbana, foi executada com a utilização de outras duas bases: a base de unidades geotécnicas delimitadas por Nishiyama (1998), em escala 1:100.000, e a imagem de satélite QuickBird QBCP, escala 1:2000, de julho/2007, com verificação no Google Earth. 
Após delimitação da bacia, foi iniciada a demarcação preliminar das unidades de materiais inconsolidados através da integração das bases acima mencionadas e definição de uma chave de interpretação. Todas as unidades mapeadas foram verificadas em campo.

O Quadro 1 apresenta, de forma resumida, os três pilares da metodologia proposta por Zuquette e Gandolfi (2004), adotada na presente pesquisa. Baseou-se, sobretudo, nas características dos materiais inconsolidados e nos ensaios do coeficiente de permeabilidade (k).

Quadro 1 - Síntese Metodológica, conforme ZUQUETTE, GANDOLFI (2004, p.62).

\begin{tabular}{|c|c|c|}
\hline \multirow{7}{*}{ Coleta de informações } & \multirow{3}{*}{ Informações prévias } & Referencial bibliográfico \\
\hline & & Histórico de inundações \\
\hline & & $\begin{array}{l}\text { Dados pluviométricos } \mathrm{e} \\
\text { pluviográficos }\end{array}$ \\
\hline & \multirow{4}{*}{ Obtenção de informações } & $\begin{array}{l}\text { Imagens de satélites/ carta } \\
\text { topográfica }\end{array}$ \\
\hline & & Trabalho de campo \\
\hline & & Amostragens \\
\hline & & $\begin{array}{l}\text { Ensaios de laboratório e } \\
\text { campo. }\end{array}$ \\
\hline \multirow[t]{2}{*}{ Processamento de dados } & \multirow[t]{2}{*}{ Tabulações das informações } & $\begin{array}{l}\begin{array}{l}\text { Integração dos dados de } \\
\text { diversas formas }\end{array} \\
\end{array}$ \\
\hline & & Banco de dados \\
\hline \multirow{7}{*}{$\begin{array}{l}\text { Análise e interpretação dos } \\
\text { dados para a elaboração de } \\
\text { documentos cartográficos }\end{array}$} & \multirow{4}{*}{ Cartas preliminares } & $\begin{array}{l}\text { MDT (Modelo Digital do } \\
\text { Terreno) }\end{array}$ \\
\hline & & Declividade \\
\hline & & $\begin{array}{l}\text { Determinação dos pontos de } \\
\text { amostragem }\end{array}$ \\
\hline & & $\begin{array}{l}\text { Classificação das Imagens de } \\
\text { satélites }\end{array}$ \\
\hline & Análises estatísticas & $\begin{array}{l}\text { Análise descritiva dos pontos } \\
\text { amostrados (Gráficos) }\end{array}$ \\
\hline & \multirow[b]{2}{*}{ Análises espaciais } & Matrizes \\
\hline & & $\begin{array}{l}\text { Carta de Unidades de } \\
\text { materiais inconsolidados da } \\
\text { bacia do córrego São Pedro }\end{array}$ \\
\hline Mapa geoambiental & $\begin{array}{l}\text { Análise } \\
\text { (integrada) }\end{array}$ & $\begin{array}{l}\text { Sugestão de locais para } \\
\text { implantação de medidas } \\
\text { estruturais para remediação } \\
\text { e prevenção de inundações. }\end{array}$ \\
\hline
\end{tabular}

Fonte: Adaptado de ZUQUETTE e GANDOLFI, 2004, P.62 
Para determinar os pontos para coleta de amostras para os ensaios de laboratório, utilizou-se o método das áreas chaves, conforme metodologia preconizada nos países do leste europeu, descrita em Zuquette (1987). A posição dos pontos de amostragem foi definida de forma não aleatória, visto que já haviam sido delimitadas as unidades de material inconsolidados. Outro parâmetro que influenciou na escolha dos locais de amostragem foi o uso do solo urbano, que inviabilizou uma amostragem uniforme. $\mathrm{O}$ método das áreas chaves pode ser utilizado para uma área mínima de $10 \mathrm{~km}^{2}$, possibilitando a produção de dados confiáveis com um número de amostragem reduzido, o que viabiliza os investimentos nos trabalhos de campo e ensaios de laboratório.

Para a área de estudo de 48,201 $\mathrm{km}^{2}$ e com base na homogeneidade das unidades de materiais inconsolidados, foram considerados inicialmente dois pontos por $\mathrm{km}^{2}$ para amostragem. Desta forma, resultaram em aproximadamente 96 pontos de coleta de amostra. Porém, devido ao custo da coleta, repetitividade e semelhança das amostras, foram selecionados 77 locais de amostragem. Entretanto, 5 pontos não foram amostrados devido à ocupação antrópica como, por exemplo, existência de aterros com resíduos da construção civil e edificações. Com isto, restaram 72 pontos de amostragem distribuídos pelas áreas das unidades de materiais inconsolidados. Para padronizar as informações das amostragens e organizar os dados de campo utilizou-se uma ficha, que foi elaborada por Nossa (2004) em sua dissertação de mestrado.

Foi utilizado um trado manual espiral de 4" até uma profundidade de $100 \mathrm{~cm}$. Também utilizou-se um trado mecânico VULCAN modelo VPS-520 capaz de atingir a profundidade de $80 \mathrm{~cm}$. A coleta de amostra deformada de solo foi, entretanto, realizada na profundidade de $100 \mathrm{~cm}$, sendo utilizado o trado manual para se atingir a profundidade final. O Trado mecânico foi necessário apenas em situações de solo muito compactado. Ao retirar as amostras realizou-se uma caracterização preliminar visual e táctil com a 
aplicação do teste de impregnação e de dilatância, conforme procedimentos indicados por Nogueira (2005).

\section{a) Classificação do solo}

As amostras de solo foram encaminhadas ao Laboratório de Geotecnia da Faculdade de Engenharia Civil da Universidade Federal de Uberlândia para realização de ensaios de determinação de massa específica dos grãos, granulometria e limites de Atterberg. Para execução do ensaio granulométrico, foram adotadas as normas NBR 7181/84, ABNT NBR 7250/1982 e ABNT NBR 6508/1984. A norma NBR 7181/84 sugere a análise do solo utilizando uma combinação de peneiramento e sedimentação. Os limites de liquidez e de plasticidade foram obtidos, respectivamente, mediante a aplicação das Normas da ABNT NBR 6459/84 e NBR 7180/84.

Foi adotado o Sistema Unificado de Classificação de Solos (SUCS). Embora ele seja utilizado principalmente por geotécnicos que trabalham em barragens, foi bastante útil para o entendimento das características mecânicas e de comportamento dos solos da área de estudo. De acordo com Pinto (2006), o sistema de Classificação Unificada foi elaborado pelo Professor Casagrande (apud Pinto 2006), no qual os solos são classificados em três grandes grupos: solos grossos, finos e turfas.

Solos de granulação grossa, segundo a SUCS, são classificados de acordo com a sua fração granulométrica predominante como pedregulho ou areia, seguido pelas suas características secundárias. A primeira análise verifica se a amostra tem poucos finos (menos do que 5\% passando na peneira $n^{0}$ 200). Desse modo deve-se verificar a sua composição granulométrica. Os solos granulares podem ser classificados como "bemgraduados", ou seja, com os diâmetros das partículas dentro de um pequeno intervalo de variação e "mal-graduados", com as partículas se situando em 
uma extensa faixa de diâmetros. Para quantificar esses solos emprega-se tanto o "coeficiente de não uniformidade" quanto o "coeficiente de curvatura" (PINTO, 2006).

De acordo com Pinto (2006), o solo bem-graduado ocorre quando o valor de CC (Coeficiente de Curvatura) está entre 1 e 3. Quando este valor está abaixo de 1 ocorre uma descontinuidade na curva granulométrica. Ao passo que no valor acima de 3 a curva tende a ser uniforme na parte central. Se a amostra, na faixa de granulação grosseira tiver entre 5 e $12 \%$ de finos, o sistema apresentará duas características secundárias (uniformidade granulométrica e propriedade dos finos), resultando em uma classificação intermediária. Por fim, quando o solo de granulação grosseira obtém mais de $12 \%$ de finos é necessário compreender as propriedades dos finos, que são definidas pela carta de plasticidade (PINTO, 2006).

A granulação fina é representada pelo silte (M), argila (C) e solo orgânico (O), que são classificados de acordo com a fração granulométrica (silte e argila). Entretanto, o comportamento da argila é analisado pelo seu teor e pela sua atividade com os índices de consistência (PINTO, 2006). O índice de plasticidade (IP) de acordo com a classificação de Casagrande apud Pinto (2006) para os solos argilosos apresentam pontos acima da "Linha A" na Figura 2. Já os solos siltosos estão apresentados abaixo da "Linha A".

A compressibilidade é uma característica complementar no solo fino, ou seja, quanto maior o seu Limite de Liquidez, mais compressíveis serão os solos. Sendo este valor superior a 50 a compressibilidade $(\mathrm{H})$ será alta. Já se for inferior é de baixa compressibilidade (L). Esta propriedade também está apresentada na Figura 2 na "Linha B" (PINTO, 2006). Quando o índice fica próximo das linhas "A" e "B" ou sobre a faixa de IP 4 a 7, são consideradas as duas classificações. Dessa forma, a classificação fica sendo a mais completa possível. A Figura 3 apresenta, de acordo com Pinto (2006), o esquema da classificação do Sistema Unificado. 
Figura 2 - Diagrama de Plasticidade

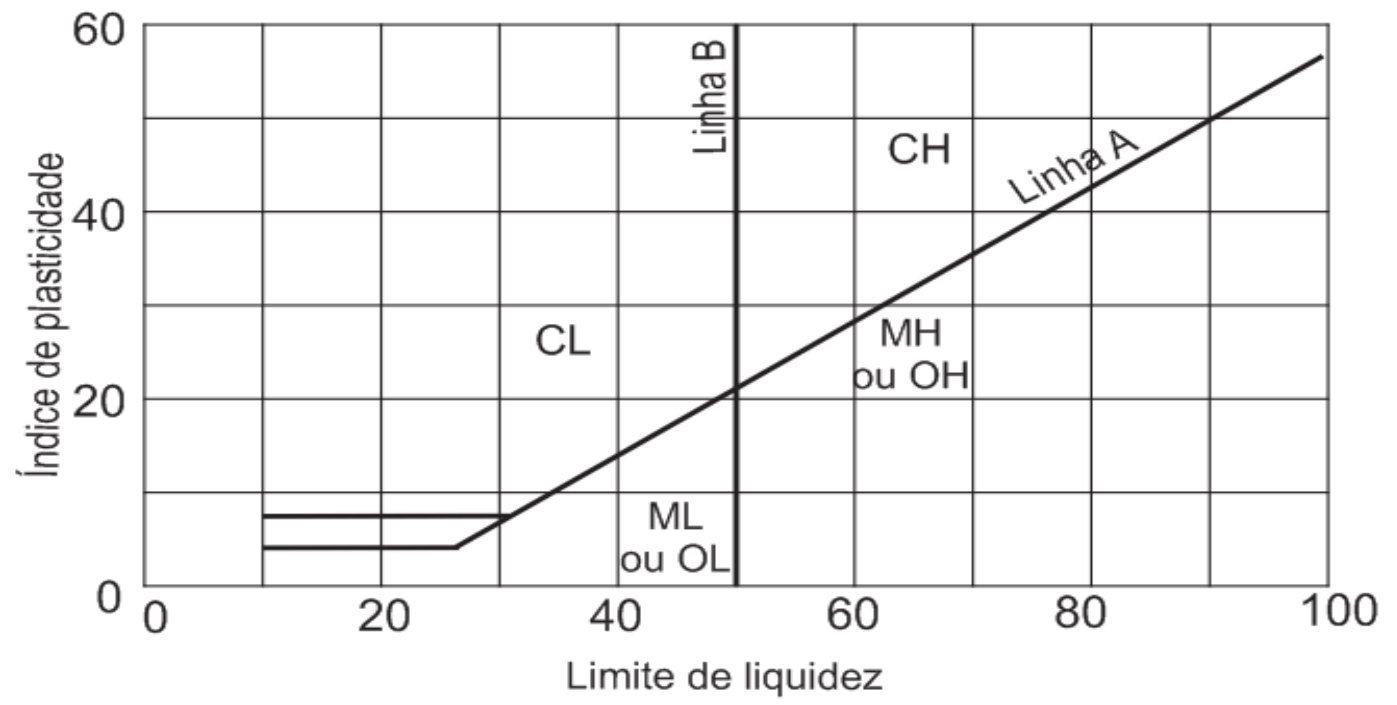

Fonte: PINTO, 2006, p. 68

Figura 3 - Esquema de classificação do Sistema Unificado

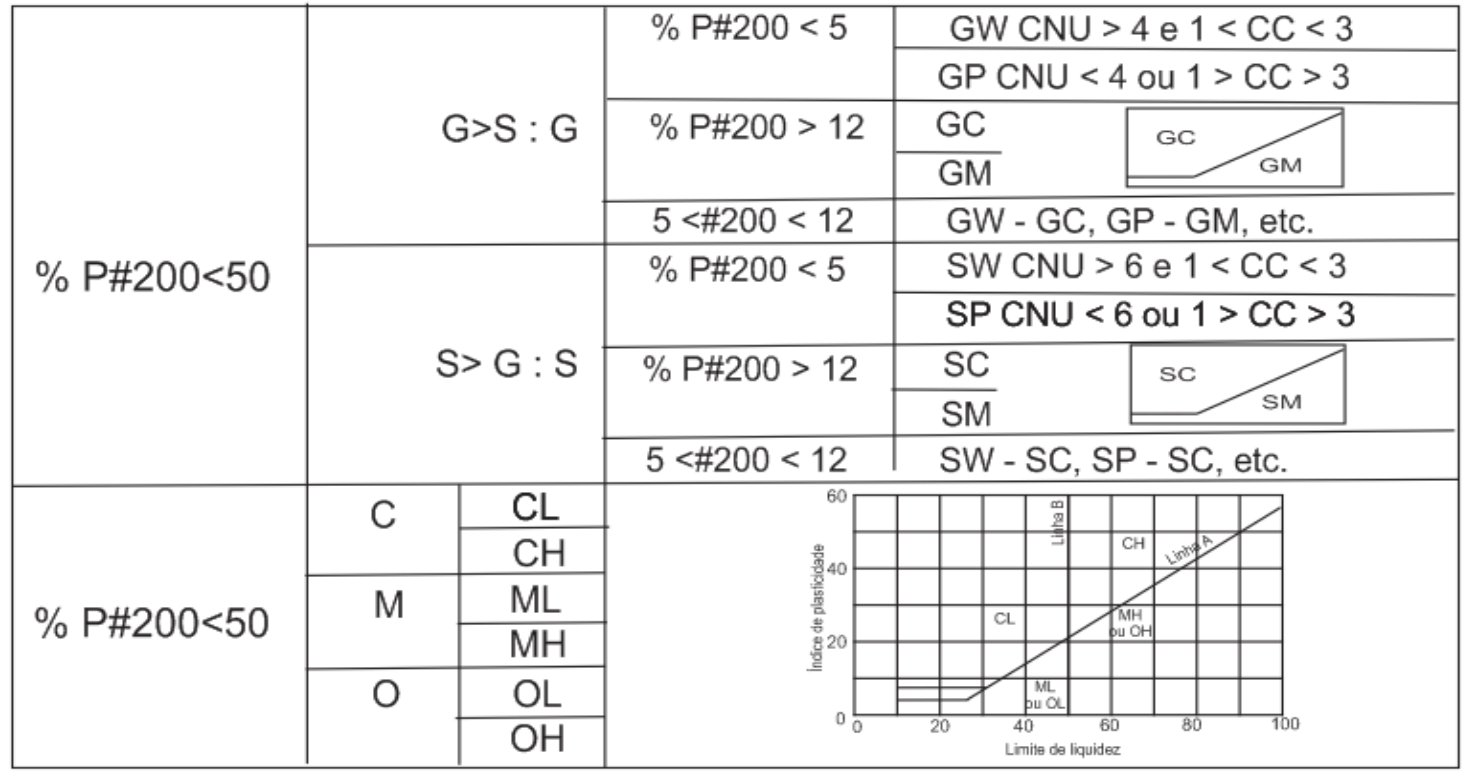

Fonte: PINTO, 2006, p. 69

b) Ensaio in situ com permeâmetro de Guelph

A delimitação das unidades homogêneas antecedeu a realização dos ensaios de infiltração de água com uso de permeâmetro Guelph. Ressalta-se 
que na unidade Orgânico/Hidromórfico não foi realizado este ensaio em razão de o solo se encontrar saturado ou com significativa saturação. Tal condição de saturação implicaria na execução do ensaio de bombeamento, sendo este adequado para situações em que o trecho ensaiado se situa abaixo do nível d'água. Foram selecionados 40 locais na área de estudo para realizar os ensaios com o Permeâmetro Guelph.

De acordo com Soto (1999), o permeâmetro Guelph foi desenvolvido por Reynolds e Elrick e aprimorado em 1985 na University of Guelph, Canadá. É utilizado de forma simples em campo requerendo apenas furos realizados a trado, com um regime permanente de suprimento de água e com cargas piezométricas constantes. Ele gera dados confiáveis para a determinação da condutividade hidráulica não saturada do solo (k). O permeâmetro Guelph pode ser utilizado tanto na superfície do solo quanto no perfil de solo com o fornecimento de água, conservando a carga hidráulica constante e conhecida.

Após os ensaios, houve a interpretação dos resultados, que foi baseada no método teórico desenvolvidos por Reynolds e Elrick (1983), com adequações na equação de Richards (1931) para fluxo permanente num furo cilíndrico. Na determinação os parâmetros de infiltração dos solos utiliza-se o método de uma carga hidráulica (COSTA E NISHIYAMA, 2007apud ELRICK et al., 1989). Esse método consiste em aplicar uma altura de carga hidráulica $\mathrm{H}$ constante e quando o regime permanente é atingido, a vazão $\mathrm{Q}$ e a condutividade hidráulica de campo $\left(\mathrm{Kf}_{\mathrm{s}}\right)$ são determinadas. Entretanto, ao realizar a reclassificação da legenda utiliza-se natural breaks, quando os intervalos são agrupados de acordo com as amostras, em razão de sua heterogeneidade. 


\section{Análise de dados e elaboração dos mapas}

Os mapas temáticos foram elaborados conforme os parâmetros do meio físico avaliados. Para realizar estes mapas foram seguidas três etapas: (i) o pré-processamento, (ii), processamento sensu strictu, e (iii) geração dos mapas. No (i) pré-processamento ocorreu um complexo levantamento dos dados cartográficos, com a adequação da área de estudo, seleção das áreas de materiais inconsolidados, seleção das áreas de ensaio em campo e coleta de dados.

No (ii) processamento, foi aplicada a interpolação dos dados de campo e laboratório utilizando o método de Kriging Ordinary (não ocorre tendência nos dados) com o modelo de semivariograma esférico, que é o padrão e obteve maior heterogeneidade nos dados. Além disso, também foram incorporados dados secundários existentes nos estudos de Nishiyama (1998) e Beicher (2001). De posse deste processamento, gerou-se a espacialização das concentrações de argila, SAP (silte, argila e pedregulho), coeficientes de permeabilidade para a profundidade de $10 \mathrm{~cm}$ e $40 \mathrm{~cm}$, entre outros.

Outro processamento realizado neste trabalho foi a aplicação da álgebra de mapas para realizar o mapa geoambiental de potencial de infiltração, que utiliza o mapa do substrato rochoso, da profundidade do nível de água (NA) (Nishiyama, 1988) e das unidades de materiais inconsolidados. Em seguida, deste resultado realizou-se mais uma sobreposição do mapa de permeabilidade para a profundidade de $40 \mathrm{~cm}$ para gerar o mapa de adequabilidade à infiltração.

E por fim, a geração dos mapas finais (iii) foi feita com a análise tanto do mapa geoambiental de potencial de infiltração quando da carta de adequabilidade de infiltração. Desta forma, foi possível obter áreas propícias à infiltração, voltadas para implantação de estruturas para infiltração das águas pluviais. 


\section{Resultados}

O mapa hipsométrico apresentado na Figura 04 indica que na área do limite da bacia do córrego São Pedro o relevo tem um decaimento suave constatado pela amplitude entre as cotas de 940 e 910 m. Em razão da baixa declividade do terreno na área próxima do divisor de águas percebe-se o favorecimento da infiltração de água e, consequentemente, a redução do escoamento superficial. Já, na área próxima a foz da bacia, o relevo possui uma amplitude abrupta partindo da cota 810 para $770 \mathrm{~m}$, o que possibilita o comportamento topográfico inverso da área de cabeceira da bacia.

Figura 4 - Mapa de Hipsometria

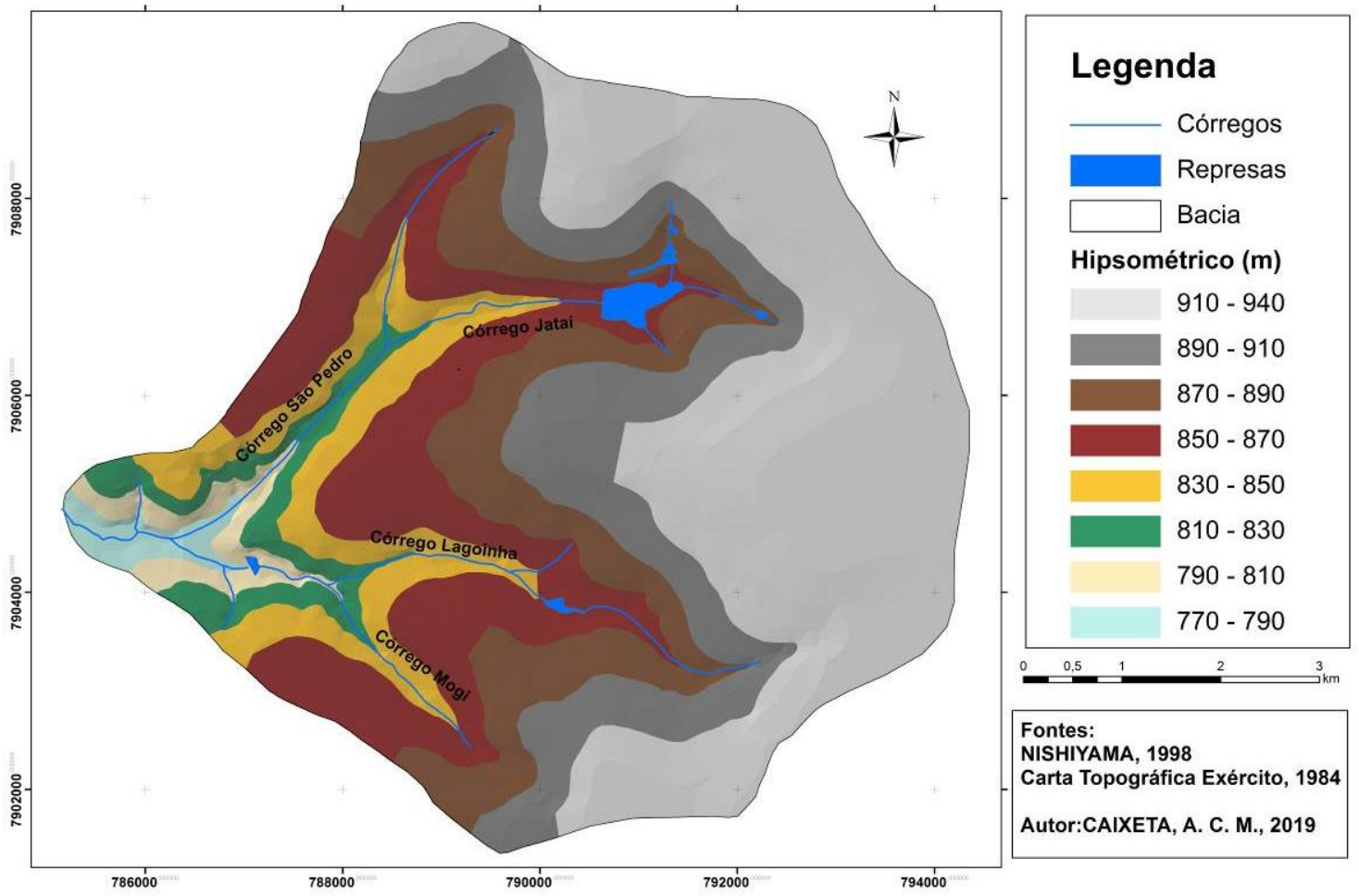

Elaborado: Autores, 2019

A Figura 5 apresenta a interpolação das porcentagens de argila na área da bacia. A partir das análises granulométricas, verificou-se que os 
valores de argila variam entre 12 e $53 \%$. Os locais de maior concentração estão próximos ao divisor de águas da bacia, nas proximidades da foz do córrego principal e também na área de nascente do córrego Lagoinha.

Os maiores valores de concentração da fração argila estão presentes na porção de cabeceira do córrego Lagoinha (acima de 40\%). Com aproximadamente $8 \mathrm{~km}^{2}$ (16,5\% da área), poderia ser considerada como a área menos permeável da bacia do córrego São Pedro. Entretanto, é necessário integrar as porcentagens de argilas com os dados de permeabilidade obtidos em campo para comprovar se estas áreas com maior concentração de argilas realmente se caracterizam como de menor permeabilidade. De posse destes dados foi possível relacionar a infiltração de água com o escoamento superficial.

Figura 5 - Mapa de concentração de fração argila nos materiais inconsolidados

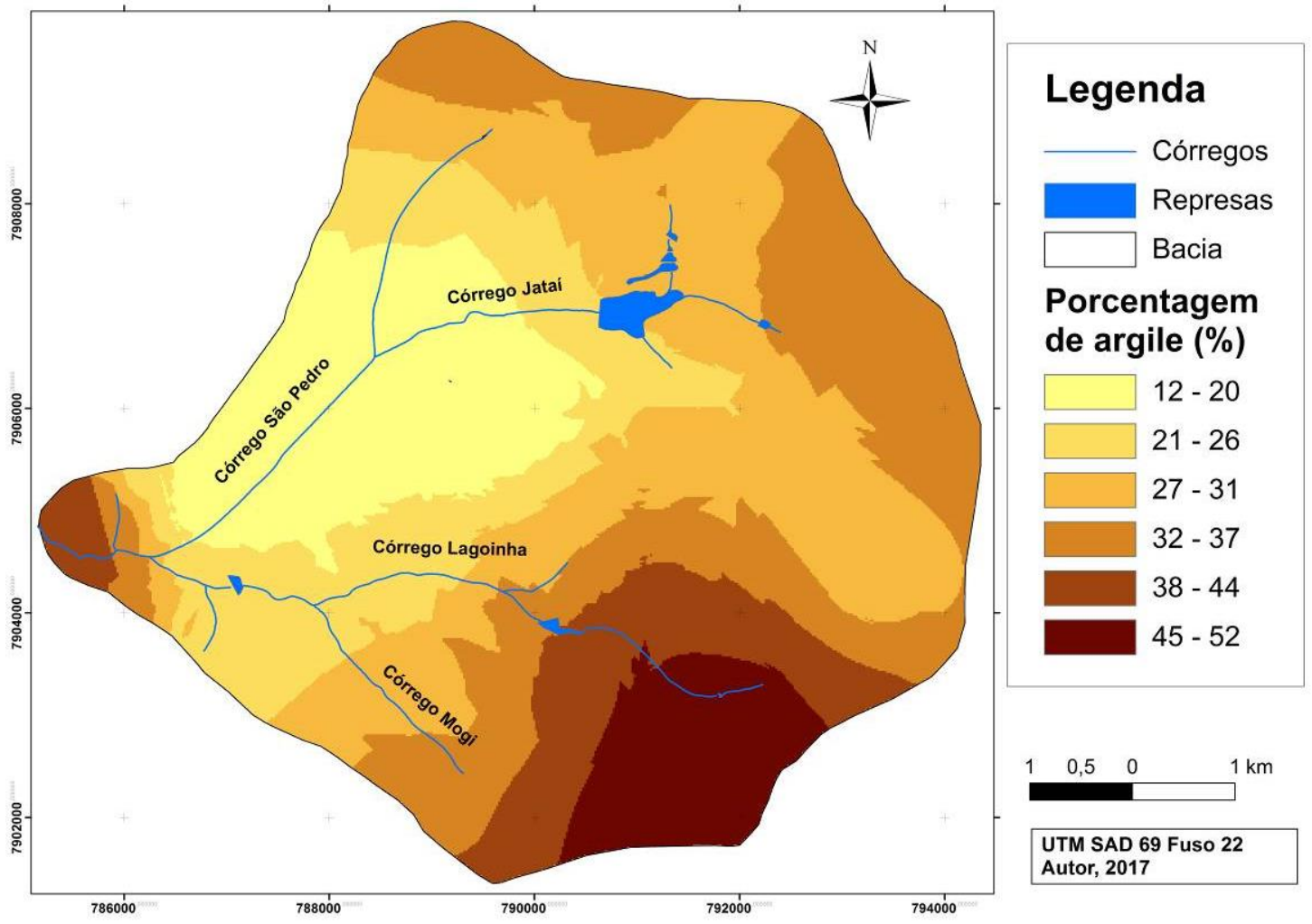

Elaborado: Autores, 2017 
Sabe-se que o silte, a areia e o pedregulho apresentam boas características para a infiltração de água, com valores crescentes da fração mais fina para a mais grossa. Por isso, neste trabalho procurou-se integrar as três frações granulométricas na análise comportamental do solo para a infiltração de água, adotando-se a designação SAP (Silte/Areia/Pedregulho). A Figura 6 apresenta o mapa resultante da interpolação da soma dos valores das porcentagens granulométricas das frações silte, areias e pedregulhos.

Figura 6 - Mapa das porcentagens de SAP encontrados nos materiais inconsolidados

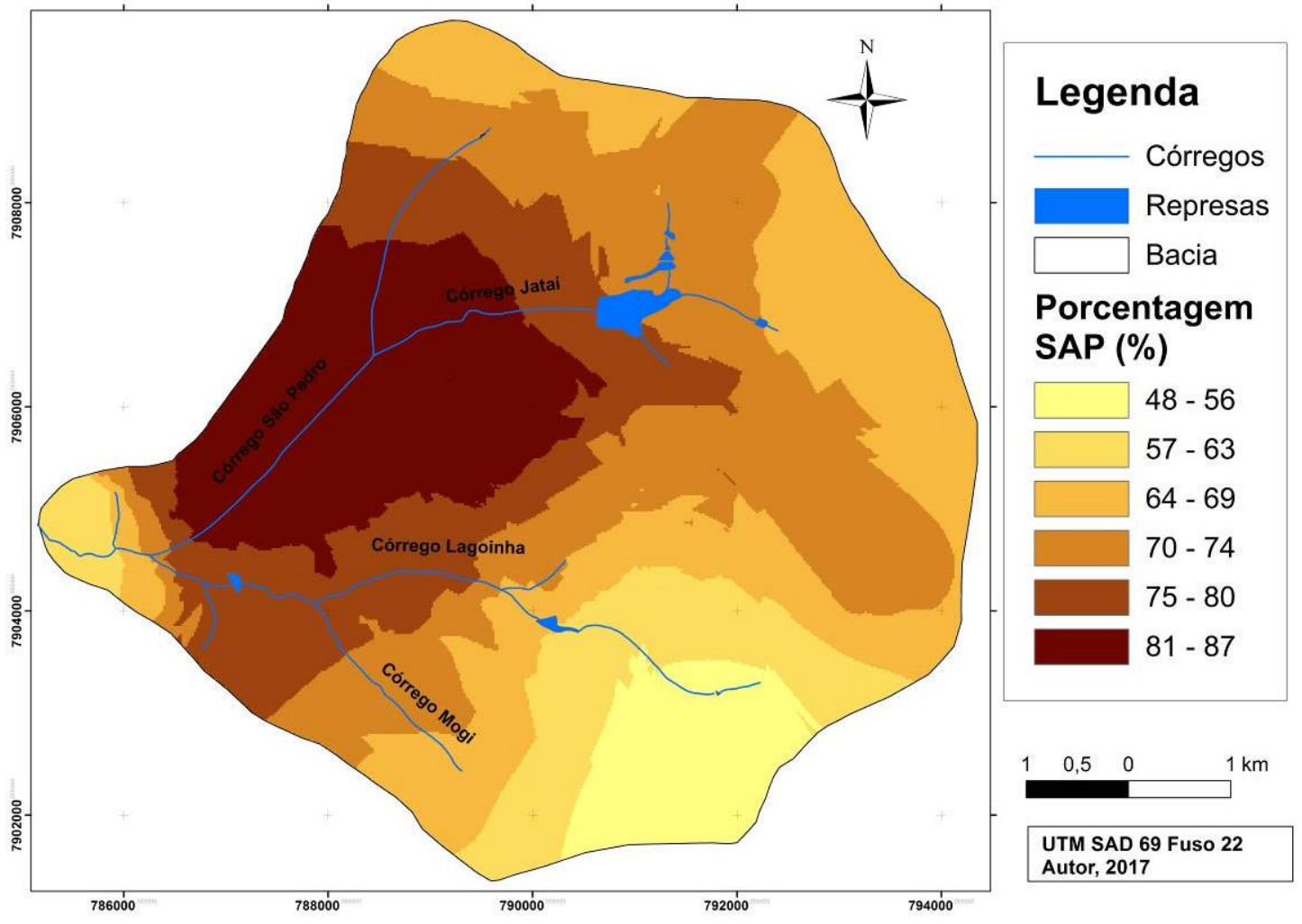

Elaborado: Autores, 2017

De acordo com a Figura 6, a área adjacente ao córrego São Pedro possui cerca de $80 \%$ de SAP. Na foz do córrego São Pedro estes valores passam para aproximadamente 50\%. Entretanto, a maioria da classificação granulométrica presente nesta área é a fração argila, colaborando para a não infiltração e o aumento do escoamento superficial. 
As áreas de nascentes dos córregos São Pedro e Jataí possuem 70\% de SAP. O córrego Mogi possui 65\% e, por fim o córrego Lagoinha, possui 55\% de SAP. Com isto, percebe que a presença de SAP é maior no centro-oeste da bacia.

\section{Coeficiente de permeabilidade (k)}

Outro parâmetro fundamental para compreender a infiltração de água no solo é a permeabilidade. A Figura 7 apresenta o mapa do coeficiente de permeabilidade para a profundidade de $10 \mathrm{~cm}$. Aparentemente os solos desta profundidade possuem maior dificuldade para permitir a passagem da água quando comparada com a profundidade de $40 \mathrm{~cm}$ (Figura 8). Percebe-se que ao norte, próximo da foz e na vertente esquerda do córrego São Pedro há uma baixa permeabilidade atingindo valores de $4,74 \times 10-6 \mathrm{~cm} / \mathrm{s}$. Já as altas permeabilidades podem ser encontradas entre os córregos Lagoinha e Mogi, chegando a $3,62 \times 10^{-3} \mathrm{~cm} / \mathrm{s}$. Outros dois locais de destaque, com elevados coeficientes de permeabilidade, localizam-se na nascente do córrego Lagoinha e no centro da bacia.

A permeabilidade para a profundidade de $40 \mathrm{~cm}$ (Figura 8) apresenta valores mais elevados na região leste da bacia, próximo à nascente do córrego Lagoinha. Nas nascentes dos córregos Lagoinha e Jataí percebe-se uma permeabilidade variando entre $1,36 \times 10^{-3} \mathrm{~cm} / \mathrm{s}$ e $1,5 \times 10^{-3} \mathrm{~cm} / \mathrm{s}$. Por fim, a nascente do córrego São Pedro possui a permeabilidade menor comparada com as outras nascentes. 
Figura 7 - Interpolação pelo método Krigagem esférico dos coeficientes de permeabilidade para profundidade de $10 \mathrm{~cm}$

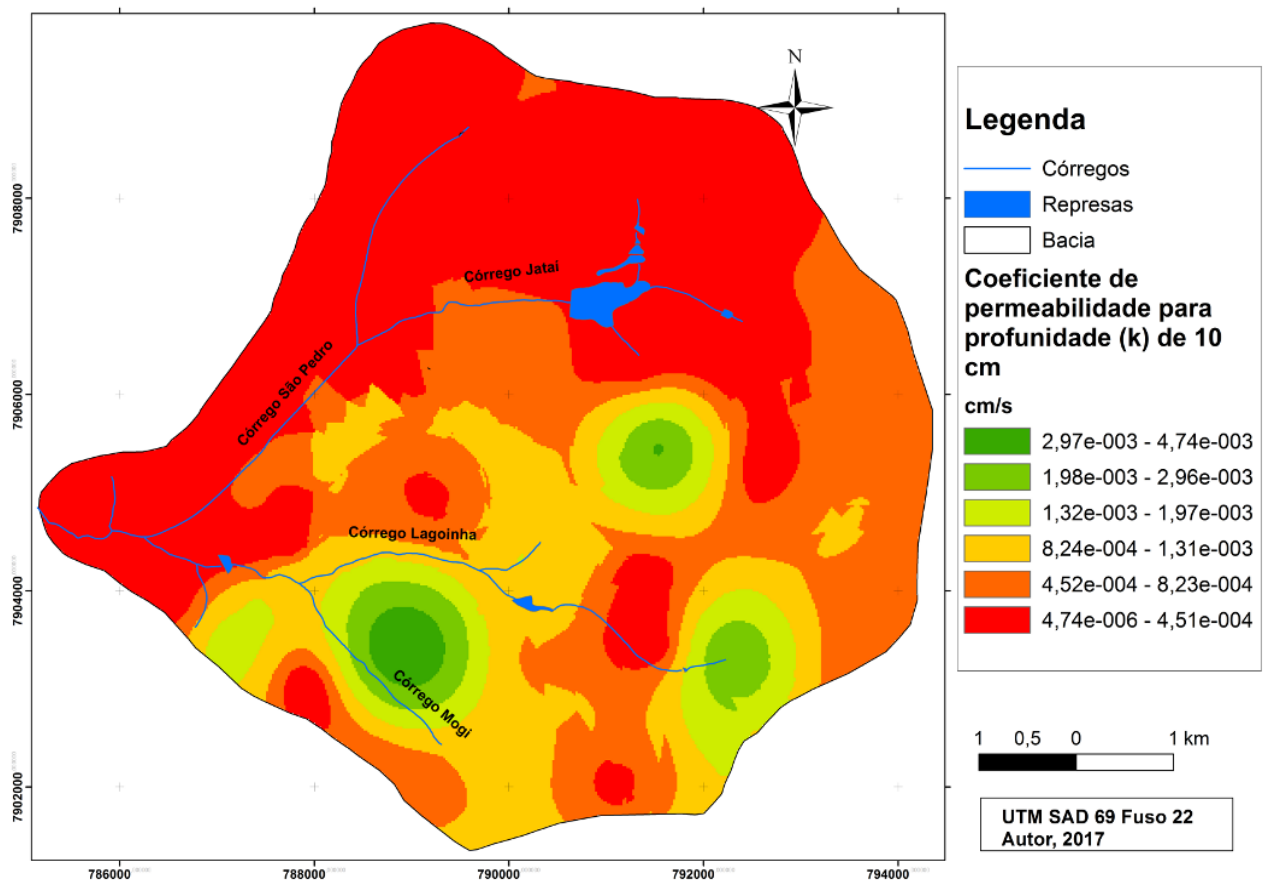

Elaborado: Autores, 2017

Figura 8 - Interpolação pelo método Krigagem esférico dos coeficientes de permeabilidade para profundidade de $40 \mathrm{~cm}$
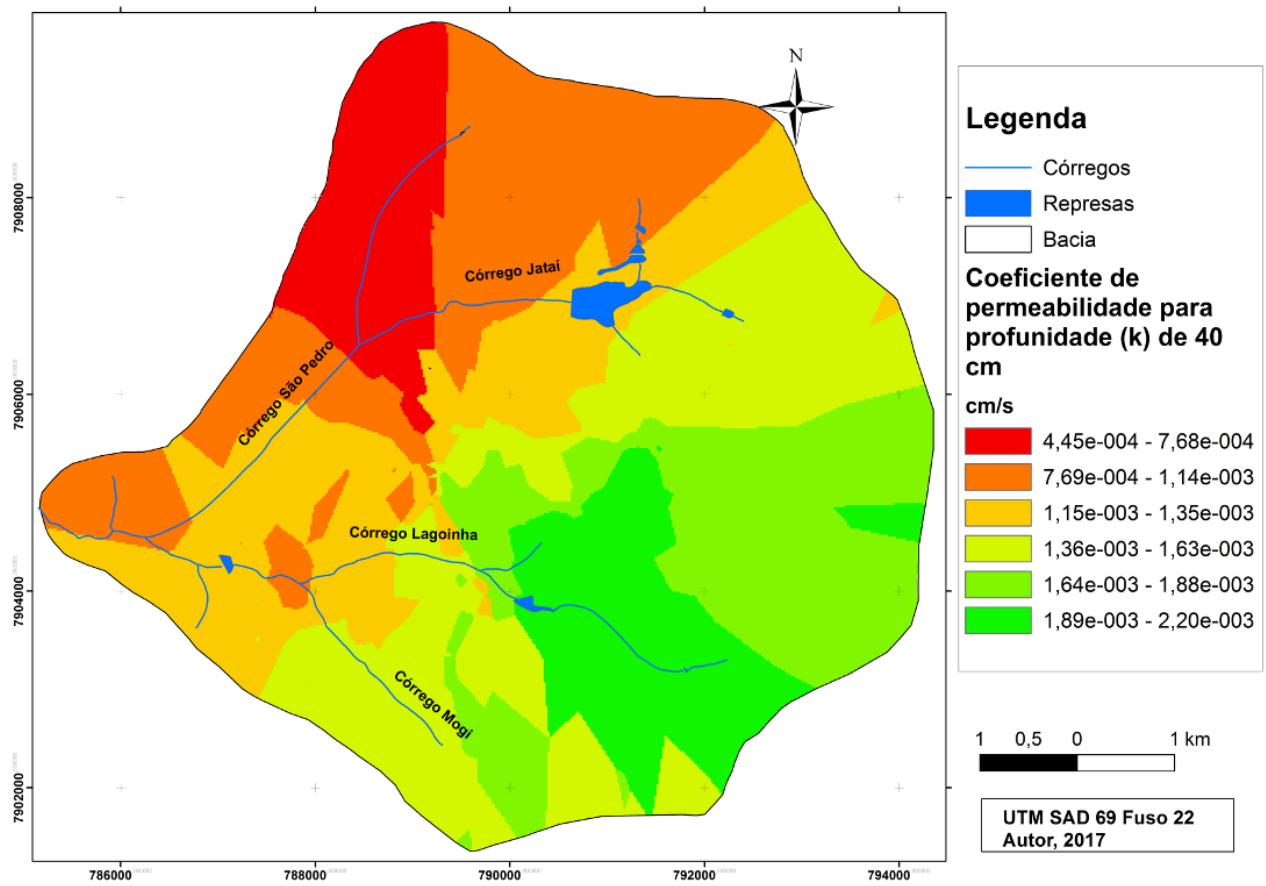

Elaborado: Autores, 2017 


\section{Infiltração e adequabilidade de infiltração}

A integração dos dados das porcentagens de argilas e de permeabilidade permitiu estimar o processo de infiltração. No centro da bacia do córrego São Pedro há uma área muito favorável à infiltração, principalmente entre os córregos Lagoinha e Mogi e entre Jataí e Lagoinha (Figura 9). Já as áreas próximas ao divisor de águas apresentam capacidade de infiltração moderada. A porção situada próximo à foz do córrego São Pedro apresenta valores reduzidos de infiltração, por apresentar alta porcentagem de argila e baixa permeabilidade.

Figura 9 - Áreas com possibilidade a infiltração geradas da integração das porcentagens de fração argila com o coeficiente de permeabilidade para a profundidade de $10 \mathrm{~cm}$ sobrepostas ao substrato rochoso

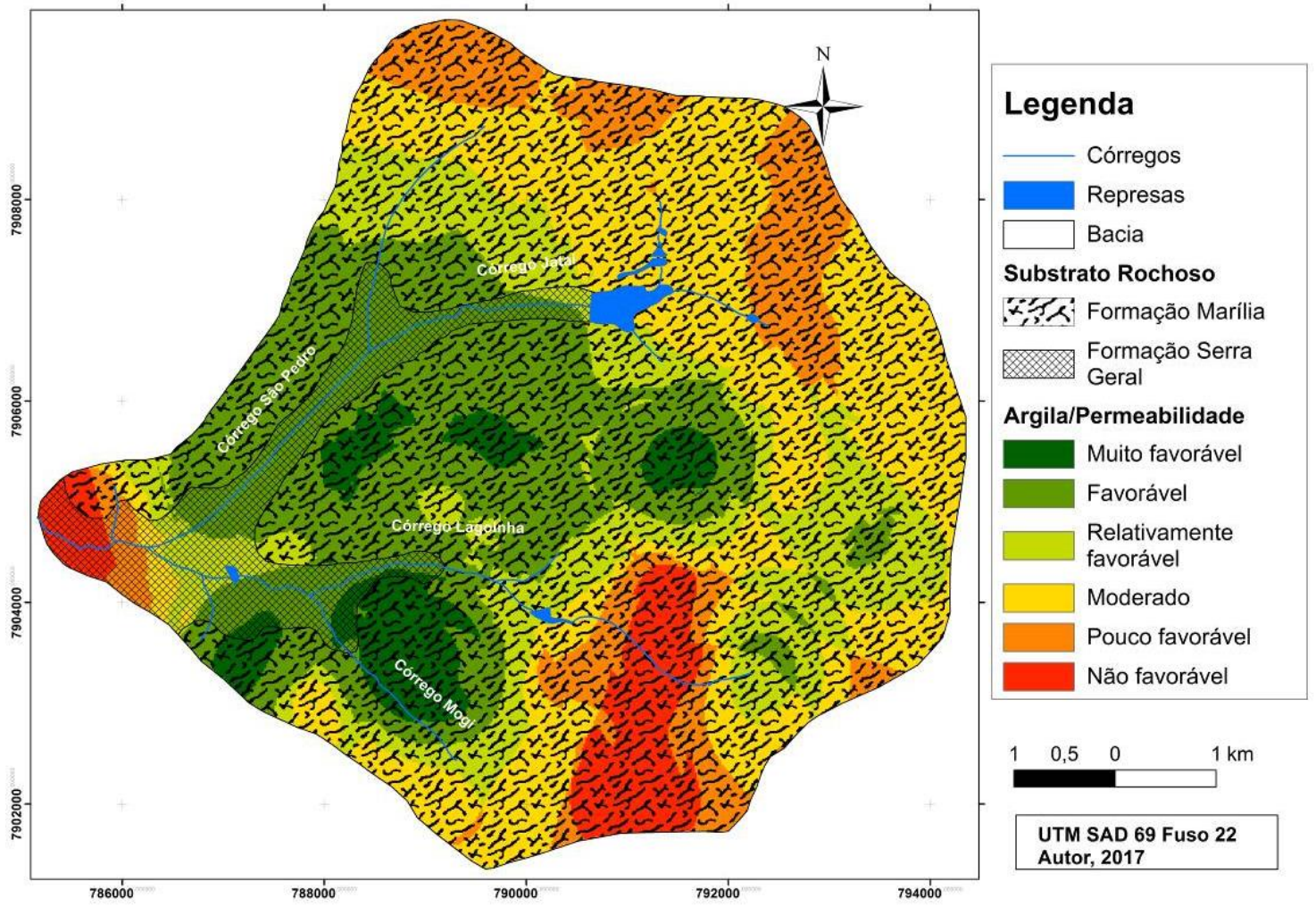

Elaborado: Autores, 2017 
A Figura 9 mostra a área de exposição da Formação Serra Geral apresentando classes que indicam favorecimento à infiltração. Mas esta formação é caracterizada por Nishiyama (1998) como basaltos com estrutura maciça, vesículo-amigloidal (base e topo de derrames) e intensamente diaclasado que pode dificultar a infiltração em alguns locais. Já nas áreas de cabeceira e no centro da bacia o substrato rochoso corresponde, de acordo com Nishiyama (1998), à Formação Marília. Esta é representada por arenitos imaturos, arenitos conglomeráticos e conglomerados. Percebe-se que a integração dos percentuais para a profundidade de $10 \mathrm{~cm}$ resulta em áreas não favoráveis à infiltração. Destaca-se a região central da bacia classificada como muito favorável e favorável à infiltração.

A redução das áreas favoráveis à infiltração na porção de ocorrência do substrato Serra Geral é confirmada diante da sobreposição do substrato com as porcentagens de argilas e a permeabilidade da profundidade de 40 cm (Figura 10). Observam-se porções mais favoráveis à infiltração entre os córregos Lagoinha e Mogi.

A avaliação da profundidade do lençol freático possibilita determinar a espessura da zona não saturada para infiltração da água. $\mathrm{O}$ nível de água freática mapeado por Nishiyama (1998) e Beicher (2001) foi sobreposto às cotas altimétricas para determinar a espessura da zona não saturada na área de estudo. 
Figura 10 - Áreas com possibilidade a infiltração geradas da integração das porcentagens de fração argilas com o coeficiente de permeabilidade para a profundidade de $40 \mathrm{~cm}$ sobrepostas ao substrato rochoso

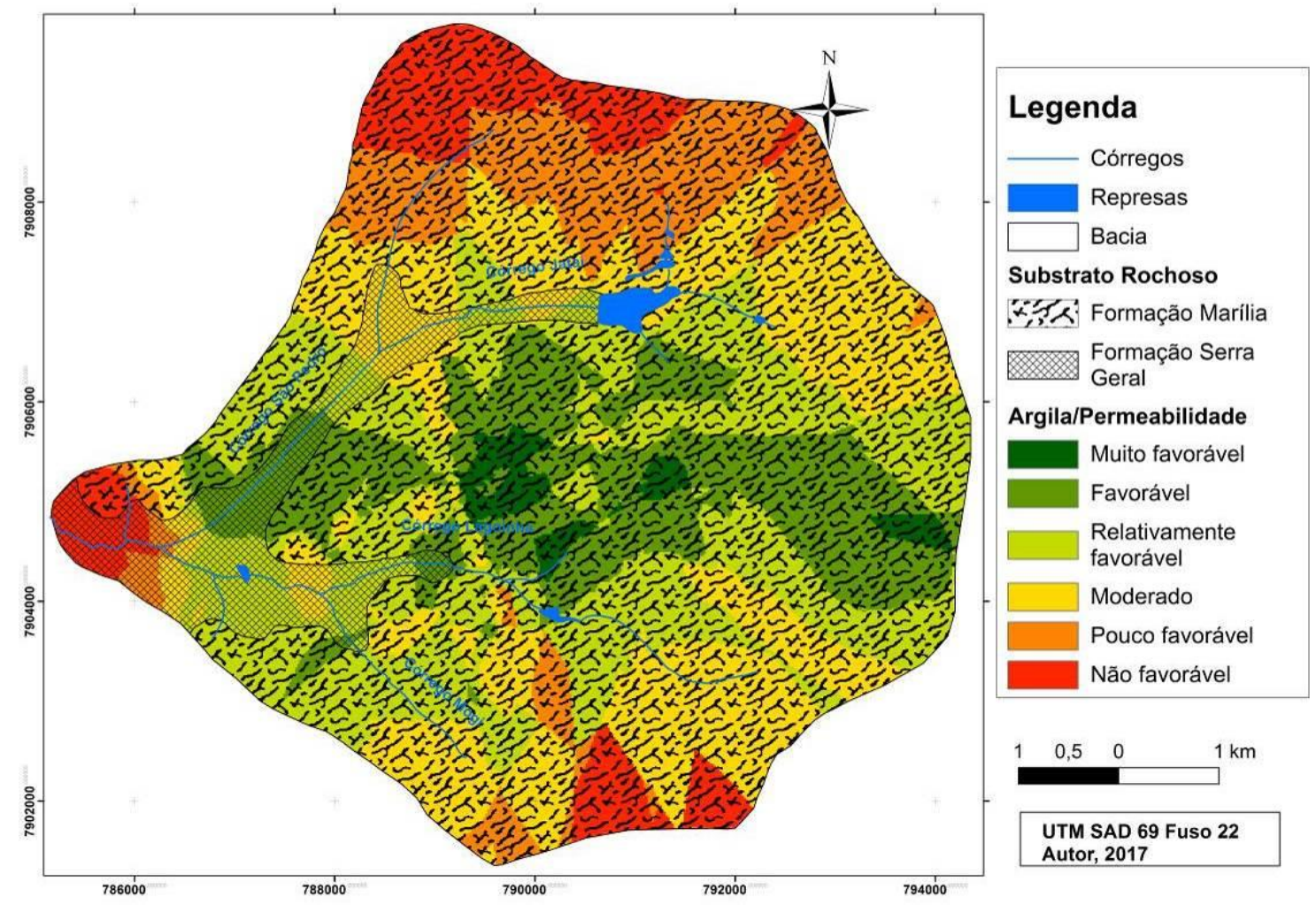

Elaborado: Autores, 2017

A Figura 11 apresenta a integração entre o nível de água freática e o coeficiente de permeabilidade (k) para profundidade de $40 \mathrm{~cm}$. Verifica-se que a região sul da bacia possui um profundo nível, acima de 20 metros e entre 10 e 20 metros para coeficiente de permeabilidade de $10^{-3}$. 
Figura 11 - Nível de água freática integrado ao coeficiente de permeabilidade (k) para a profundidade de $40 \mathrm{~cm}$

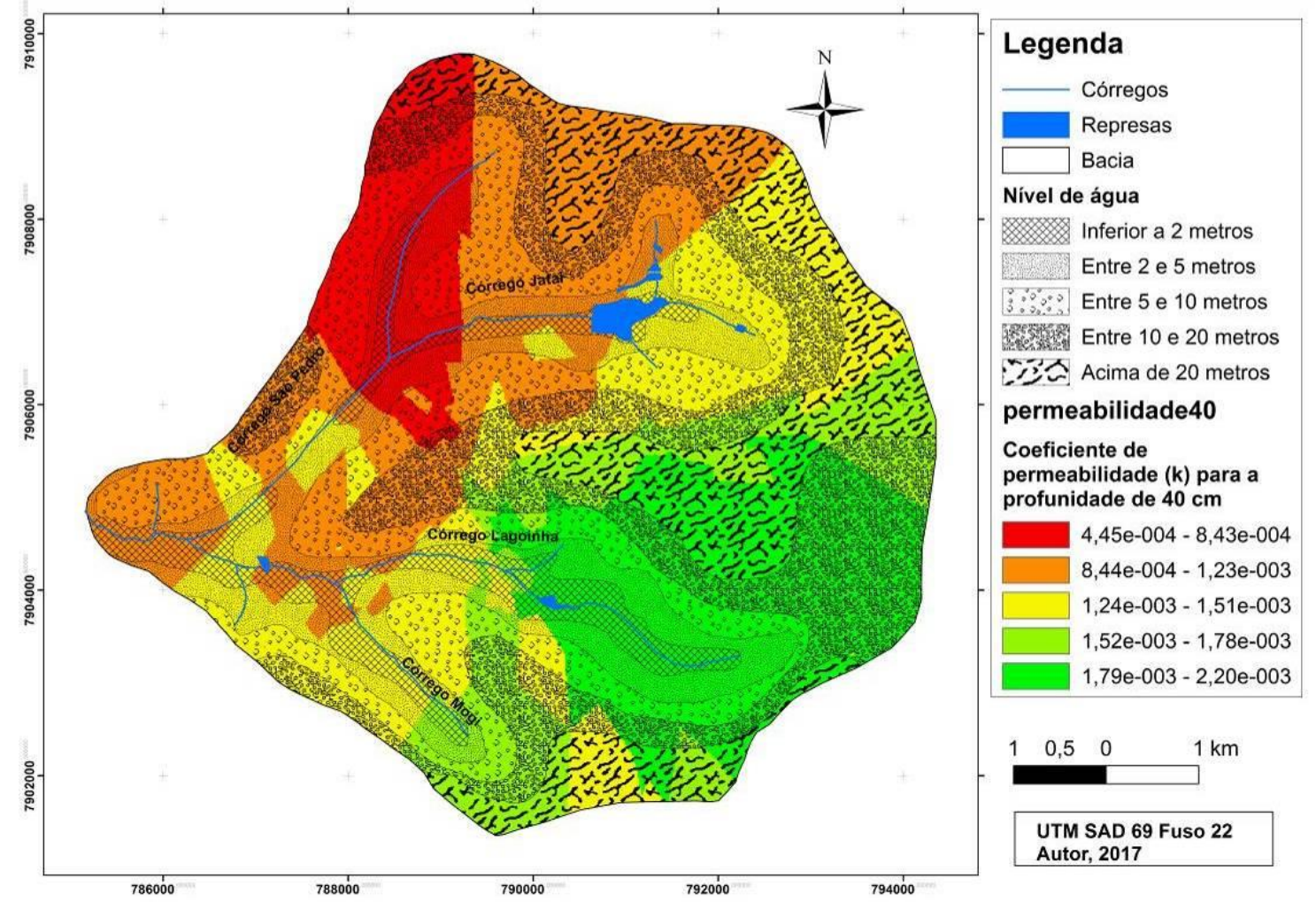

Elaborado: Autores, 2017

A Figura 12 apresenta adequabilidade de infiltração. Observa-se que próximo aos canais e na foz do córrego São Pedro não é adequado para infiltração corroborando para a formação das inundações. Assim, percebe-se o aumento da inundação tanto por características naturais quanto pela ocupação antrópica, comprovando a necessidade de medidas de contenção da água. As áreas situadas próximo ao divisor de água obtiveram os maiores valores que são favoráveis a infiltração.

Ressalta-se que a região norte da bacia, próxima ao córrego São Pedro, possui uma densa urbanização reduzindo a possibilidade de implantação de medidas estruturais e não estruturais. Mas, é fundamental a sua inserção no Plano de Drenagem Urbana como, por exemplo, 
determinando percentuais de área verde ou implantação de áreas de captação de água de chuva nos telhados ou implantação de telhados verdes.

Figura 12 - Mapa de adequabilidade de infiltração

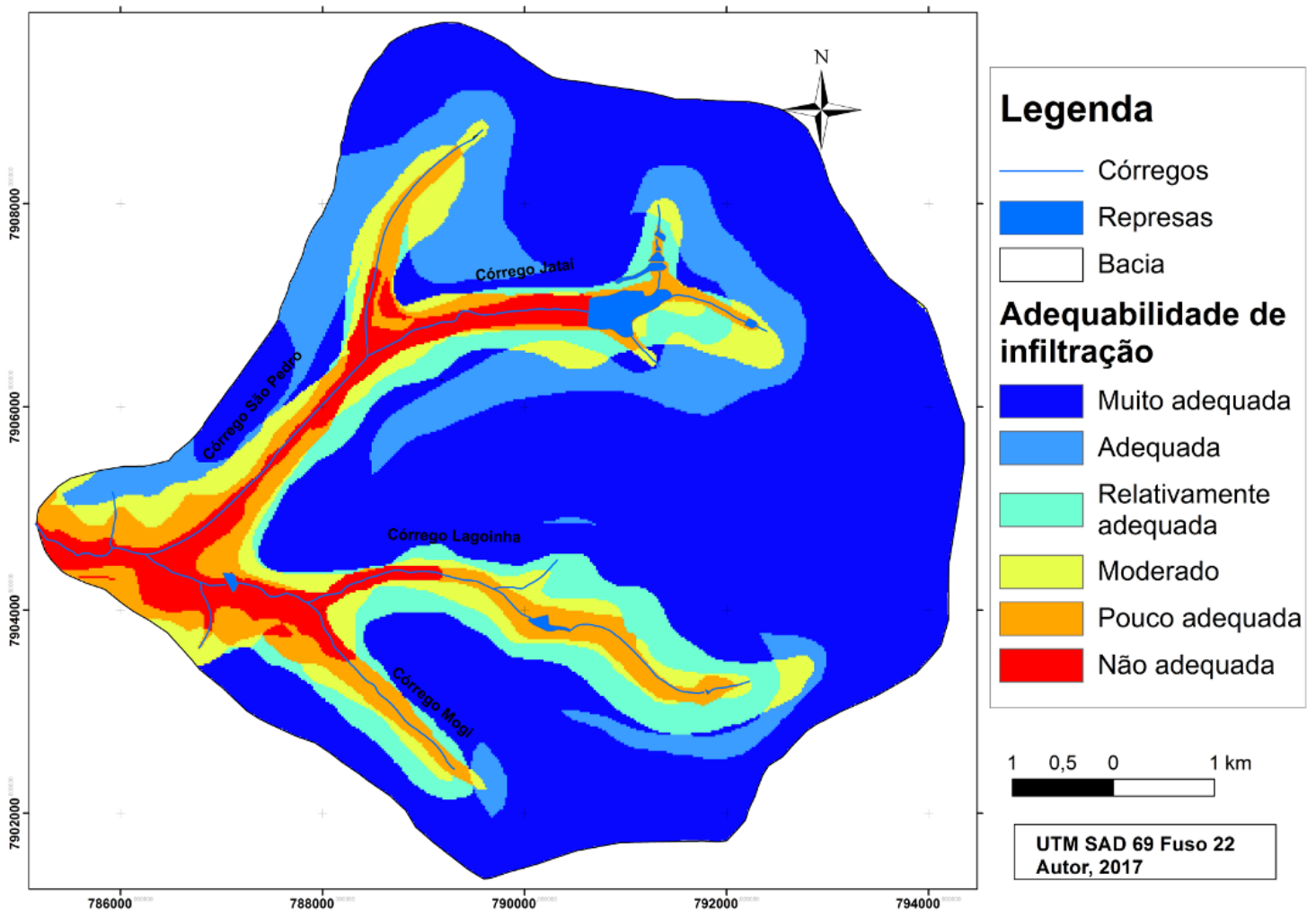

Elaborado: Autores, 2017

Alguns locais sem urbanização poderiam ser utilizados para implantação de medidas estruturais para retenção de água pluvial, como a criação de bolsões, pavimentos permeáveis e parques. Outra sugestão que poderia ser utilizada nestas áreas que ainda não possui uma densa urbanização é especificar a zona de ocupação com um parcelamento maior do que está previsto no plano diretor de Uberlândia. Entre os córregos Mogi e Lagoinha, por exemplo, há extensas áreas ainda não ocupadas. 


\section{Considerações Finais}

O conjunto de mapas permite a análise integrada de informações importantes do ponto de vista geotécnico e geoambiental, intervenientes nos processos de infiltração e escoamento superficial. Foi constatado que a porção sul da bacia apresenta alta concentração de argila e menores valores de fração silte. Nas áreas adjacentes ao córrego São Pedro há cerca de 80\% de valores de SAP (Silte/Areia/Pedregulho).

A região do centro, nos divisores dos principais córregos da bacia, possui áreas mais favoráveis à infiltração. Outra área de destaque para infiltração é a região sul da bacia, que possui um profundo nível freático, aproximadamente 20 metros, além de um coeficiente de permeabilidade $(\mathrm{k})$ de $10^{-3}$. Para a bacia como um todo, foi observado valores de $\mathrm{k}$ variando entre as ordens de grandeza de $10^{-4}$ a $10^{-5} \mathrm{~cm} / \mathrm{s}$

A pesquisa ampliou o nível de conhecimento acerca do comportamento hidrológico da bacia, indicando sua potencialidade de infiltração maior próximo aos divisores de água e sua restrição à infiltração próximos aos córregos e na foz do córrego principal. Este conjunto de informações pode ser utilizado pelas diferentes áreas do conhecimento que tratam de tal questão. Espera-se, ainda, que os dados gerados pelo trabalho ofereçam subsídios ao planejamento do uso e ocupação do solo e escolha de áreas onde estudos devem ser realizados em escalas de maior detalhe, sempre com o objetivo de controlar inundações com um custo de manejo menor.

Os episódios de inundação adjacentes ao córrego São Pedro são determinados pelas características geotécnicas e geoambientais e pela ocupação antrópica. Elas devem ser inseridas e consideradas no Plano de Drenagem Urbana de Uberlândia. A ocupação urbana ainda está expandindo, principalmente na direção sul, na qual ainda existem parcelas significativas de áreas verdes para serem ocupadas. Assim, fica um alerta e uma análise da bacia do córrego São Pedro para os gestores urbanos. 


\title{
Referências
}

\begin{abstract}
ABNT - ASSOCIAÇÃO BRASILEIRA DE NORMAS TÉCNICAS. Agregado para concreto. NBR7211. Rio de Janeiro: ABNT, 2005.

ABNT - ASSOCIAÇÃO BRASILEIRA DE NORMAS TÉCNICAS. Rochas e Solos Terminologia. NBR6502. Rio de Janeiro, ABNT, 1995.

ABNT - ASSOCIAÇÃO BRASILEIRA DE NORMAS TÉCNICAS. Solo - Análise granulométrica - Método de ensaio - Procedimento: NBR7181. Rio de Janeiro, ABNT, 1984.
\end{abstract}

ABNT - ASSOCIAÇÃO BRASILEIRA DE NORMAS TÉCNICAS. Solo - Determinação do limite de liquidez: NBR 6459. Rio de Janeiro, ABNT, 1984.

ABNT - ASSOCIAÇÃO BRASILEIRA DE NORMAS TÉCNICAS. Solo - Determinação do limite de plasticidade: NBR7180, Rio de Janeiro, ABNT, 1984.

ANDRADE, S. L. FERREIRA, V. O. SILVA, M. M. Elaboração de um mapa de risco de inundações da bacia hidrográfica do córrego São Pedro, área urbana de Uberlândia-MG. Caderno de Geografia, v.24, n.41, 2014. https://doi.org/10.5752/P.23182962.2014v24n41p1.

BEICHER, E. J. Mapeamento da Profundidade da superfície freática do setor central da malha urbana de Uberlândia - MG. 2001. 68 f. Dissertação (Mestrado em Geografia). Universidade Federal de Uberlândia, 2001.

COSTA, F. M. P. ; NISHIYAMA, L. Utilização do Permeâmetro Guelph e Penetrômetro de Impacto em estudos de uso e ocupação dos solos em bacias hidrográficas. Caminhos de Geografia (UFU. Online), v. 08, p. 131-143, 2007. Disponível em: http://www.seer.ufu.br/index.php/caminhosdegeografia/article/view/15589/8823. Acesso em 14 outubro. 2015.

CAIXETA, A.C.M. NISHIYAMA, L. Caracterização morfométrica da bacia do córrego São Pedro em Uberlândia - MG utilizando técnicas de geoprocessamento. In: XXI Simpósio Brasileiro de Recursos Hídricos. 11, 2015. Brasília. Anais... Brasília: ABRH, 2015, p.1-7. Disponível em: $\quad$ http://www.evolvedoc.com.br/sbrh/detalhes-1103_caracterizacao morfometrica-da-bacia-do-corrego-sao-pedro-em-uberlandia-mg-utilizando-tecnicas de geoprocessamento. Acesso em 15 dezembro. 2015.

NISHIYAMA, Luiz. Procedimentos de mapeamento geotécnico como base para análises e avaliações ambientais do meio físico, em escala 1:100 000: aplicação no município de Uberlândia - MG. 1998. 372 f. Tese (Doutorado em Engenharia Civil). Universidade de São Paulo/São Carlos, 1998.

NOSSA, T. C. B. Mapeamento geotécnico preliminar para disposição de resíduos sólidos no município de Araxá - MG.2004. 163 f Dissertação (Mestrado em Engenharia Civil) - Universidade Federal de Uberlândia, 2004.

PINTO, C. S. Curso básico de Mecânica dos Solos. 3. ed., São Paulo - SP: Oficina de Textos, 2006. 355p

REYNOLDS, W. D.; ELRICK, D. E.; TOPP, G. C. A reexamination of the constant head well permeameter method for measuring saturated hydraulic conductivity above the water table. Soil Science, v. 136, n. 4, p. 250-268, 1983. https://doi.org/10.1097/00010694198310000-00008

RICHARDS, L. A. Capillary conduction of liquids through porous medium. Physics, 1:318333, 1931. https://doi.org/10.1063/1.1745010

SOTO, M. A. A. Estudo da condutividade hidráulica em solos não saturados. 120 p.1999 (Dissertação de Mestrado), Universidade de São Paulo/São Carlos, 1999.

TUCCI, C. E. M. Plano diretor de drenagem urbana: princípios e concepção. RBRH Revista Brasileira de Recursos Hídricos, Volume 2 n.2 Jul/Dez 1997, 5-12. https://doi.org/10.21168/rbrh.v2n2.p5-12 
ZUQUETTE, L. V. Análise crítica da cartografia geotécnica e proposta metodológica para condições brasileiras. 1987. Tese (Doutorado em Engenharia). Universidade de São Paulo/São Carlos, 1987.

ZUQUETTE, L., V. GANDOLFI, N. Cartografia Geotécnica. São Paulo: Oficina de Textos, 2004. 190p. 